УдК 338.43

\author{
КУРБАНОВ КАЗБЕК КЕРИМОВИЧ \\ к.э.н., ведущий научный сотрудник Института \\ социально-экономических исследований ДФИЦ $\rho А Н$, \\ e-mail:kkurbanov@mail.ru
}

БАБАЕВА ДИАНА РАИФОВНА

к.э.н., старший преподаватель кафедры аудита и финансового контроля ФГБОУ ВО «Дагестанский государственный

технический университет» e-mail: diana_babaeva_76@mail.ru

\title{
DOI:10.26726/1812-7096-2021-4-31-37 \\ СТРАТЕГИЧЕСКОЕ РАЗВИТИЕ АПК НА ОСНОВЕ ФОРМИРОВАНИЯ ИННОВАЦИОННЫХ ПРОЕКТОВ
}

\begin{abstract}
Аннотауия. Цель работы заключается в разработке теоретико-методологических положений и практических рекомендаций по повышению экономической эффективности стратегического развития АПК проблемного региона на основе формирования инновационных программ и проектов. Выявление особенностей региональных проблем, препятствующих активному инновационному развитию АПК, с их учетом создание в регионе организационно-экономических условий, стимулирующих развитие инновачионных процессов, позволит повысить как экономическую эффективность использования ограниченных региональных ресурсов АПК, так и усилить его конкурентоспособность на внутреннем и внешнем рынках. Методологией проведения исследования послужили труды отечественных и зарубежных ученых в области исследования теоретических и практических вопросов по организации инновационной деятельности в АПК проблемного региона, разработке методических подходов по повышению эффективности государственного регулирования инновационного развития АПК региона. В работе использованы системный анализ, общенаучные логические приемы и методы исследования. Результаты работы. Определены концептуальные подходы развития инновационной деятельности в АПК для обеспечения конкурентоспособности конечной продукиии АПК проблемного региона (на примере субтектов СКФОО). Выявлены и предложены определяющие элементы экономического механизма, способствующие ускорению инноващионного развития АПК. Предложены инноващионные подходы в АПК, позволяющие решить проблему технологического обновления отраслей АПК СКСОО и добиться роста соииально-экономической эффективности в АПК региона.

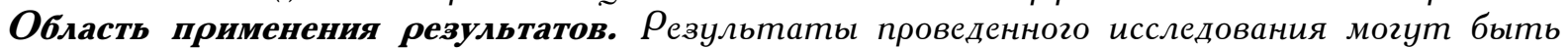
использованы органами региональной власти при разработке комплексных программ инновационного развития АПК регионов СКСОО. Разработка основных концептуальных направлений инновационной деятельности в агропромышленном производстве является основой подготовки нормативно-правовых документов, выработки инновационной политики в проблемном регионе. Выводы. Определение кониептуальных подходов и приоритетных направлений развития инновационной деятельности позволяет обеспечить техническое и технологическое обновление отраслей и сфер АПК проблемного региона и повышение его сочиально -экономической эффективности. Обоснование необходимости государственной инновационной политики в аграрном секторе посредством активизации инновационной деятельности направлено на совершенствование организационноэкономического механизма ее регулирования, повышения уровня и качества жизни на селе. Ключевые слова. АПК, проблемный регион, конкурентоспособность, инновационное развитие, техническое и технологическое обновление, иифровизация, инновационные разработки, инновационная инфраструктура, научно-техническая и инновауионная деятельность.
\end{abstract}


KURBANOV KAZBEK KERIMOVICH

Ph. D. in Economics, Leading Researcher at the Institute of Socio-Economic Research of the Russian Academy of Sciences, e-mail:kkurbanov@mail.ru

BABAEVA DIANA RAIFOVNA

$\rho h$. D. in Economics, Senior Lecturer, Department of Audit and Financial Control, Dagestan State Technical University e-mail: diana_babaeva_76@mail.ru

\title{
STRATEGIC DEVELOPMENT OF THE AGRO-INDUSTRIAL COMPLEX BASED ON FORMATION OF INNOVATIVE PROJECTS
}

\begin{abstract}
The purpose of the work is to develop theoretical and methodological provisions and practical recommendations for improving the economic efficiency of the strategic development of the agro-industrial complex of the problem region on the basis of the formation of innovative programs and projects. Identifying the features of regional problems that hinder the active innovative development of the agro-industrial complex, taking into account the creation of organizational and economic conditions in the region that stimulate the development of innovative processes, will increase both the economic efficiency of the use of limited regional resources of the agro-industrial complex, and strengthen its competitiveness in the domestic and foreign markets. The methodolo$\boldsymbol{g y}$ of the study was based on the works of domestic and foreign scientists in the field of research of theoretical and practical issues on the organization of innovative activities in the agro-industrial complex of the problem region, the development of methodological approaches to improve the efficiency of state regulation of innovative development of the agro-industrial complex of the region. The paper uses system analysis, general scientific logical techniques and research methods. sults of the work. Conceptual approaches to the development of innovative activities in the agroindustrial complex to ensure the competitiveness of the final products of the agro-industrial complex of the problem region (on the example of the subjects of the NCFD) are defined. The defining elements of the economic mechanism that contribute to the acceleration of the innovative development of the agro-industrial complex are identified and proposed. Innovative approaches in the agro-industrial complex are proposed to solve the problem of technological renewal of the agro -industrial complex of the North Caucasus Federal District and to achieve the growth of socioeconomic efficiency in the agro-industrial complex of the region. The scope of the results. The results of the study can be used by the regional authorities in the development of comprehensive programs for the innovative development of the agro-industrial complex of the regions of the North Caucasus Federal District. The development of the main conceptual directions of innovation in agro-industrial production is the basis for the preparation of regulatory documents, the development of innovation policy in the problem region. Conclusions. The definition of conceptual approaches and priority areas for the development of innovative activities allows for the technical and technological renewal of the branches and areas of the agro-industrial complex of the problem region and the increase of its socio-economic efficiency. The rationale for the need for state innovation policy in the agricultural sector through the activation of innovation activities is aimed at improving the organizational and economic mechanism of its regulation, improving the level and quality of life in rural areas.
\end{abstract}

Keywords. Agro-industrial complex, problem region, competitiveness, innovative development, technical and technological renewal, digitalization, innovative developments, innovative infrastructure, scientific, technical and innovative activities.

Введение. СКФО в географическом и геоэкономическом плане находится в благоприятном положении и может дать разные естественные ресурсы, позволяющие макрорегиону обладать выгодным превосходством, иметь существенное место в различных рейтингах социальноэкономического положения субъектов Российской Федерации. В России большое значение в ВВП экономики приходится на промышленный сектор, а аграрному сектору отведено незначительное место (около 29 \%, на более 7 \% в 2018 году). В таком пропорциональном отношении Северо-Кавказский федеральный округ имеет около 20 \% промышленности, а сельское 
хозяйство - приблизительно 16 \%. Развитие инновационной деятельности в аграрном секторе экономики макрорегиона даст толчок к росту конкурентоспособности региона и представляет дальнейший вектор развития в перспективе. Основными задачами, связанными с формированием приоритетов инновационной деятельности, являются:

- изменения в нормативно-правовом законодательстве, связанном с повышением инновационной активности в отрасли;

- формирование инновационного облика в мотивировании деятельности аграрной научной сферы;

- активизация в подготовке и переподготовке научных специалистов в сфере АПК;

- обеспечение концентрации ресурсов на приоритетных направлениях;

- формирование инфраструктуры инновационных процессов.

В настоящее время фундаментальные исследования требуют поддержки со стороны государства, особенно те, которые могут применяться в ближайшее время, и ориентированы на быструю отдачу, особенно в проблемных регионах, так как такое внедрение позволит сократить разрыв между проблемными и развитыми регионами.

Таким образом, инновационное развитие требует решения следующих задач:

- формирование инновационной инфраструктуры, т. е. решение этой задачи позволяет развиваться организациям, которые продвигают научно-техническую продукцию;

- предоставление информации и консультативных услуг, т. е. решение этой задачи позволит обеспечить инновационную деятельность информационной базой;

- предоставление экспертизы научным и инновационным проектам и программам;

- создание структуры, которая будет заниматься обеспечением финансирования научнотехнической и инновационной деятельности.

Эффективное решение выбранных приоритетных направлений инновационной деятельности позволит решить проблему технологического обновления отраслей АПК и добиться роста социально-экономической эффективности регионов СКФО.

Методы исследования. В социально-экономическом развитии СКФО АПК играет главенствующую роль. Субъекты Северо-Кавказского федерального округа располагают большим производственным потенциалом в сфере роста экономики аграрного сектора. Реализация такого потенциала представлена прежде всего такими продуктовыми подкомплексами АПК, как плодоовощной, зерновой, виноградо-винодельческий, мясо-молочный, овцепродуктовый и др.

В 2018 году в регионах Северо-Кавказского федерального округа получены следующие производственные показатели аграрного сектора экономики (таблица 1).

\begin{tabular}{|c|c|c|c|}
\hline & Млрд руб. & в \% к 2017 год & в \% к итогу \\
\hline Российская Федерация & 5119,75 & 99,4 & 100 \\
\hline СКФО & 449,47 & 98,0 & 8,8 \\
\hline РД & 124,01 & 100,7 & 2,4 \\
\hline РИ & 10,23 & 109,7 & 0,2 \\
\hline КБР & 46,89 & 101,8 & 0,9 \\
\hline КЧР & 28,05 & 101,6 & 0,6 \\
\hline $\mathrm{PCO}-\mathrm{A}$ & 25,81 & 115,7 & 0,5 \\
\hline ЧР & 24,12 & 93,9 & 0,5 \\
\hline $\begin{array}{c}\text { CK } \\
\text { CK }\end{array}$ & 190,34 & 92,7 & 3,7 \\
\hline
\end{tabular}

ально-экономическое положение Северо-Кавказского федерального округа в 2018 году. ФСГС. - М. - 2019.

Современное состояние АПК СКФО показывает, что первое место по производству продукции сельского хозяйства занимает Ставропольский край, он производит порядка 40-45 \% от всех регионов Северо-Кавказского федерального округа. Дагестан производит в пределах 
25-26 \%. Наименьший уровень занимает Ингушетия - около 1,5 \%. В Северо-Кавказском федеральном округе в 2018 году было произведено продукции сельского хозяйства на сумму около 450 млрд рублей. В регионах Северо-Кавказского федерального округа РФ сфера переработки сельскохозяйственной продукции наиболее успешными темпами развивается в Кабардино-Балкарии, от общего объема производства сфера переработки продукции сельского хозяйства занимает около 14-15\%, а самая низкая в Чечне - около $3 \%$.

В структуре аграрного производства по объемам среди федеральных округов в 2018 году сложилось следующее положение (таблица 2).

Таблийа 2

\begin{tabular}{|c|c|c|c|c|c|}
\hline & РФ & 2015 & 2016 & 2017 & 2018 \\
\hline ЦФО & 100 & 25,1 & 25,1 & 25,9 & 26,3 \\
\hline СЗФО & 100 & 4,9 & 4,8 & 4,7 & 4,6 \\
\hline ЮФО & 100 & 15,8 & 15,1 & 15,8 & 15,4 \\
\hline СКФО & 100 & 7,3 & 7,9 & 7,9 & 8,5 \\
\hline ПФО & 100 & 23,9 & 23,4 & 22,9 & 22,1 \\
\hline УФО & 100 & 6,2 & 6,2 & 6,0 & 5,8 \\
\hline СФО & 100 & 12,8 & 12,6 & 12,2 & 12,2 \\
\hline ДФО & 100 & 3,4 & 3,4 & 3,2 & 3,2 \\
\hline
\end{tabular}

ально-экономическое положение Северо-Кавказского федерального округа в 2018 году. ФСГС. - М. -2019.

Такая структура, лишь с небольшими отклонениями, сохраняется уже последние 7-8 лет. Анализ показывает, что рост среди федеральных округов РФ демонстрируют Центральный, Южный, Северо-Кавказский федеральный округа, доля Приволжского и Уральского федеральных округов понижается.

Пропорционально сельское хозяйство в ВРП Северо-Кавказского федерального округа занимает около 20-23 \%, а по отдельным субъектам СКФО достигает до 41-43\%. В современный период все регионы округа в агропромышленном производстве реализуют инновационные проекты разных масштабов.

Последние несколько лет порядка 8 тысяч га садов посажено в КБР, из них около 4 тысяч га - сады интенсивного типа. Инвестиционный объем в садово-ягодном агропромышленном кластере Кабардино-Балкарии достиг более 3,5 млрд руб.

Большой инвестиционный проект реализуется при поддержке «Корпорации развития Северного Кавказа». ЗАО «ВТБ Капитал» инвестировал более 250 млн долларов в развитие интенсивного растениеводства, проект IRRICO инвестировал средства в инновационные технологии выращивания пшеницы, кукурузы, картофеля, сои и подсолнечника, площадь освоения составила более 60 тысяч гектаров.

Предприятием с совместным капиталом AVGCAPITALPARTNERS инвестировано около 130 млн долларов в долгосрочный проект AVANGARD, проектом осуществлено оборудование на земельных площадях более 16 тыс. га. Систем дождевального орошения кругового воздействия. Кроме того, на площади более 4 тыс. га размещены элеваторы емкостью более 100 тыс. т с процессами сушки и очистки зерновых.

Стимулирование инвестиционной деятельности позволит успешно развивать сельские территории Северо-Кавказского федерального округа, в этих целях необходимо формирование агропромышленных парков различного направления. Прежде всего это модернизация агропромышленного производства, доступ к залоговому обеспечению, определенные банковские гарантии и поручительства по кредитным обязательствам, развитие микрофинансирования и микрокредитования, доступ к субсидиям приобретения современного оборудования, агролизинг, развитие машинно-тракторного парка.

Таким образом, развитие инновационных процессов, повышение инновационной активности в аграрном секторе экономики макрорегиона приобретает черты определенной модели, в 
которой взаимосвязаны научно-образовательные организации, производственные процессы и соответствующая инфраструктура. Все это приведет к максимальному использованию природно-биологического потенциала отраслей растениеводства и животноводства; к специализации и концентрации в агропромышленных предприятиях; модернизации производственной инфраструктуры; внедрения инновационных технологий в производстве и управлении отраслями сельского хозяйства и в целом АПК макрорегиона.

Построение прибыльного, высокорентабельного агропромышленного производства возможно лишь в случае внедрения новых агротехнологий, технических средств, развития материальной базы и цифровизации всей экономики агропромышленного производства. Необходимо учитывать особенности новых инновационных подходов в рамках цифровизации производственно-экономической деятельности агропромышленных предприятий.

Федеральным правительством развитию цифровой экономики в аграрном секторе экономики Российской Федерации придается огромное внимание, этому призван разработанный МСХ России ведомственный проект «Цифровое сельское хозяйство», сроки реализации которого составляют с 2019 по 2024 год. Конечная цель данного ведомственного проекта - цифровая трансформация сельского хозяйства посредством внедрения цифровых технологий и платформенных решений для обеспечения технологического прорыва в АПК и достижения роста производительности труда. Проект предусматривает цифровизацию не только хозяйствующих субъектов, но и всей системы управления АПК. Здесь предполагается сотрудничество таких крупных структур, как Министерство сельского хозяйства России, Роскосмос, Росгидрометцентр, участие различных научно-технических центров и компаний, ориентированных на внедрение высокотехнологичных инноваций в сельское хозяйство [13].

Достичь прироста эффективности, роста рентабельности, повышения производительности труда и снижения рисков за счет качественного управления технологическими процессами, а также процессами принятия решений на всех уровнях иерархии с использованием передовых способов агропроизводства с помощью внедрения цифровых технологий - цель цифровизации АПК и сельского хозяйства страны.

На современном этапе развития рыночных преобразований в экономике АПК в Российской Федерации цифровизация достигает всего 10 \%, несмотря на то, что страна является лидером на мировом пространстве по площади плодородных земель. Рейтинг цифровизации в сельском хозяйстве среди стран мира Россия составляет 15-е место.

В развитых странах мира, таких как США, точное земледелие применяется в 60 \% ферм и аграрных хозяйств, в ЕС этот показатель достигает 80 \%, а в Российской Федерации - всего лишь только в $3 \%$ сельскохозяйственных предприятий. Явно прослеживается резкое отставание развития цифровизации в АПК РФ от западных и ведущих стран мира.

Данные компании ABINBEWEFES показывают, что удельный вес специалистов по информационным технологиям среди специалистов в агробизнесе в развитых странах мира - США, ФРГ, Великобритания - примерно составляет более 4 \%. В РФ - всего около $2,5 \%$.

Цифровизация и процессы ее внедрения по-разному дифференцированы в зависимости от регионов РФ, их природно-климатических отличий и развития экономики.

Необходимо отметить, что системы точного земледелия, формирование и развитие «умных ферм», «умных теплиц» и других аграрных хозяйственных структур призваны решать определенные задачи по цифровизации сельского хозяйства.

Большое значение придается инициативам по развитию экологического мониторинга в сельских территориях путем внедрения технологий, связанных на базе информационнокоммуникационных технологий - это удаленный мониторинг состояния ферм, дистанционное управление различными сельскохозяйственными машинами и оборудованием, используя возможности огромного числа приложений для смартфонов.

В разработанном ведомственном проекте «Цифровое сельское хозяйство» на период 2019 2024 годов и в дальнейшем намечено достичь такие показатели, как рост сельскохозяйственного производства продукции, отраслей сельского хозяйства в 1,3-1,5 раза; снижение трудоемкости сельскохозяйственного производства в 1,5-1,7 раза; повышение качественных характеристик продукции сельского хозяйства; снижение себестоимости и конечной цены на продукцию сельского хозяйства; сокращение расходов различных видов энергии и материалов; 
рост урожайности продукции растениеводства в 1,4 раза; снижение импортозависимости сельскохозяйственных машин и оборудования, их аппаратных и программных средств; автоматизация, роботизация, продвижение интеллектуальных машинных технологий.

Результаты. Таким образом, инновационное развитие требует решения следующих задач: формирование инновационной инфраструктуры, т. е. развитие организаций, которые продвигают научно-техническую продукцию; предоставление информации и консультативных услуг, т. е. обеспечение инновационной деятельности информационной базой; предоставление экспертизы научным и инновационным проектам и программам; создание структуры, которая

Литература

1. Астахова Т. Н., Колбанев М. О., Шамин А. А. Деиентрализованная ичифровая платформа сельского хозяйства // Вестник НГИЭИ. - 2018. - Т. 6 (85). - С. 5-17.

2. Балиянц К. М. Основные факторы эффективного использования ресурсного потенциала сельских территорий Республики Дагестан / К. М. Балияни, А. З. Джамбулатова, С. В. Дохолян, Ю. Д. Умавов // Экономика устойчивого развития. - 2019. - № 1 (37). - С. 92-96.

3. Курбанов К. К. Агропромышленный кластер как эффективный инструмент регионального маркетинга // Вопросы структуризации экономики. - 2014. - № 2. - C. 21-22.

4. Курбанов К. К. Материально -техническая база как основа устойчивого развития агропроизводства в регионе / М. А. Гасанов, К. К. Курбанов // Региональные проблемы преобразования экономики. 2013. - № 2 (36). - C. $187-193$

5. Курбанов К. К. Инновачионное развитие регионального АПК: кластерный подход / К. К. Курбанов // Региональные проблемы преобразования экономики. - 2017. - № 4 (78). - C. 43-50.

6. Курбанов К. К. Роль и значение АПК СКФО в инновачионном развитии проблемного региона // Вопроcы структуризации экономики. - 2019. - № 4. ИСЭИ ДФИЦ РАН.

7. Курбанов К. К. Устойчивое развитие АПК СКФО: инноваџии и цичфровизация экономики / К. К. Курбанов, П. Д. Камилова, М. А. -Г. Кардашова // Экономика и предпринимательство. - 2020. - oo 5 (118). - C. 432-437.

8. Минсельхоз взял цифровой АПК на себя. [Электронный ресурс]. Режим доступа: https:// www.comnews.ru/content/121130/2019-07-31/(дата обращчения 11.03.2020), свободный. - Загл. с экраHa.

9. Официальный сайт Федеральной службы государственной статистики. [Электронньй ресурс]. Режим достуnа: http://www.gks.ru/free doc/new site/m sraMi/26-30-l.htm, свободный. - Загл. с экрана.

10. Продовольственный рынок регионов России: новый вектор развития // Лаврикова Ю.Г. и др. Екатеринбург, 2018.

11. Регионы России. Социально -экономические показатели. - 2017: Стат. сб. / Росстат. - M., 2018. $1326 \mathrm{c}$.

12. Сочиально-экономическое положение Северо-Кавказского федерального округа в 2018 году. ФСГС. - М. -2019.

13. Юнусова П. С. Инновационное развитие АПК как инструмент мобилизации ресурсного потенциала // Региональные проблемы преобразования экономики. - 2013. - №. 3 (37). - С. 170-173.

14. Юнусова П. С. Модернизаџия - основа роста конкурентоспособности агропромышленного комплекса / П. С. Юнусова // Региональные проблемы преобразования экономики. - 2017. - № 2 (76). - С. 20 -27.

15. J’Son\&Partners «Текущее состояние АПК в России и мире (на примере США, Китая, Индии и Россuи)».

16. Mamai O. Current Trends in Development of Public-Private Partnership in Agrarian Sector of Regional Economy / O. Mamai, R. Nekrasov, V. Parsova // Proceedings of the 2018 International Conference «Economic Science for Rural Development». No. 47. Jelgava, LLU ESAF, 2018. P. 189-195.

17. Research and development in agricultural robotics: A perspective of digital farming / Redmond RaminShamshiri, Cornelia Weltzien, Ibrahim A. Hameed, Ian J. Yule, Tony E. Grift, Siva K. Balasundram, LenkaPitonakova, Desa Ahmad, Girish Chowdhary // Int J Agric\&Biol Eng. Vol. 11. No. 4. 2018.14 c.

\section{References:}

1. Astahova T. N., Kolbanev M. O., SHamin A. A. Decentralizovannaya cifrovaya platforma sel'skogo hozyajstva // Vestnik NGIEI. - 2018. - T. 6 (85). - S. 5-17.

2. Baliyanc K. M. Osnovnye faktory effektivnogo ispol'zovaniya resursnogo potenciala sel'skih territorij Respubliki Dagestan / K. M. Baliyanc, A. Z. Dzhambulatova, S. V. Doholyan, YU. D. Umavov // Ekonomika ustojchivogo razvitiya. - 2019. - № 1 (37). - S. 92-96.

3. Kurbanov K. K. Agropromyshlennyj klaster kak effektivnyj instrument regional'nogo marketinga // Voprosy strukturizacii ekonomiki. - 2014. - № 2. - S. 21-22.

4. Kurbanov K. K. Material'no -tekhnicheskaya baza kak osnova ustojchivogo razvitiya agroproizvodstva $v$ regione / M. A. Gasanov, K. K. Kurbanov // Regional'nye problemy preobrazovaniya ekonomiki. - 2013. - № 2 (36). - S. $187-193$.

5. Kurbanov K. K. Innovacionnoe razvitie regional'nogo APK: klasternyj podhod / K. K. Kurbanov // Regional'nye problemy preobrazovaniya ekonomiki. - 2017. - № 4 (78). - S. 43-50.

6. Kurbanov K. K. Rol' i znachenie APK SKFO v innovacionnom razvitii problemnogo regiona // Voprosy strukturizacii ekonomiki. - 2019. - № 4. ISEI DFIC RAN. 
7. Kurbanov K. K. Ustojchivoe razvitie APK SKFO: innovacii i cifrovizaciya ekonomiki / K. K. Kurbanov, P. D. Kamilova, M. A. -G. Kardashova // Ekonomika i predprinimatel'stvo. - 2020. - № 5 (118). - S. $432-437$.

8. Minsel'hoz vzyal cifrovoj APK na sebya. [Elektronnyj resurs]. Rezhim dostupa: https://www.comnews.ru/ content/121130/2019-07-31/(data obrashcheniya 11.03.2020), svobodnyj. - Zagl. s ekrana.

9. Oficial'nyj sajt Federal'noj sluzhby gosudarstvennoj statistiki. [Elektronnyj resurs]. Rezhim dostupa: http:// www.gks.ru/free_doc/new_site/m_sraMi/26-30-l.htm, svobodnyj. - Zagl. s ekrana.

10. Prodovol'stvennyj rynōk regionov Rossii: novyj vektor razvitiya // Lavrikova YU.G. i dr. Ekaterinburg, 2018.

11. Regiony Rossii. Social'no -ekonomicheskie pokazateli. - 2017: Stat. sb. / Rosstat. - M., 2018. - 1326 s.

12. Social'no-ekonomicheskoe polozhenie Severo-Kavkazskogo federal'nogo okruga v 2018 godu. FSGS. - M. 2019.

13. YUnusova P. S. Innovacionnoe razvitie APK kak instrument mobilizacii resursnogo potenciala // Regional'nye problemy preobrazovaniya ekonomiki. - 2013. - №. 3 (37). - S. 170-173.

14. YUnusova P. S. Modernizaciya - osnova rosta konkurentosposobnosti agropromyshlennogo kompleksa / P S. YUnusova // Regional'nye problemy preobrazovaniya ekonomiki. - 2017. - № 2 (76). - S. 20-27.

15. J'Son\&Partners «Tekushchee sostoyanie APK v Rossii i mire (na primere SSHA, Kitaya, Indii $i$ Rossii)».

16. Mamai O. Current Trends in Development of Public-Private Partnership in Agrarian Sector of Regional Economy / O. Mamai, R. Nekrasov, V. Parsova // Proceedings of the 2018 International Conference «Economic Science for Rural Development». No. 47. Jelgava, LLU ESAF, 2018. P. 189-195.

17. Research and development in agricultural robotics: A perspective of digital farming / Redmond RaminShamshiri, Cornelia Weltzien, Ibrahim A. Hameed, Ian J. Yule, Tony E. Grift, Siva K. Balasundram, LenkaPitonakova, Desa Ahmad, Girish Chowdhary // Int J Agric\&Biol Eng. Vol. 11. No. 4. 2018.14 s. 